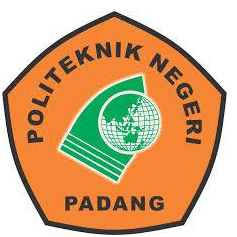

Jurnal IImiah Rekayasa Sipil

Available online at : http://ejournal2.pnp.ac.id/index.php/iirs/

Terakreditasi SINTA Peringkat 5

\title{
Analisis Debit Banjir Rancangan Sub DAS Air Bengkulu Menggunakan Analisis Frekuensi dan Metode Distribusi
}

\author{
${ }^{1}$ Gusta Gunawan, ${ }^{2}$ Besperi, ${ }^{3}$ Liza Purnama \\ 1,2,3 Teknik Sipil, Fakultas Teknik, Universitas Bengkulu \\ '1g.gunawan@unib.ac.id, ${ }^{2}$ besperi mt@unib.ac.id, 3 liza@gmail.com
}

\begin{abstract}
The Design discharge is the important data needed for design of the water infrastructure. The purpose of this study is to estimate the design discharge with a variety of timesusing a frequency analysis in the Air Bengkulu Sub-watershed. Rain fall data were obtained from the BMKG of Bengkulu province, its starting from 2009 to 2018 years. The design flood estimation method used a statistical method. It is using the distribution method. The initial stage of the research is to process rain data and then conduct frequency analysis. The mathematical equation for frequency analysis includes statistical equations to determine the average value, standard deviation, coefficient of variation, skewness coefficient and kurtosis coefficient. The method used in determining the type of distribution for frequency analysis in this study uses the Gumbel Type I distribution method, Pearson Log Type III, Normal, and Normal Log. Distribution fit test was performed with chi square test and Kalmogorof Smirnov test. The results of estimated design discharges for the 2 years return period, 5 years return period, 10 years return period, 25 years return period, 50 years return periodand 100 years returns period in the Air Bengkulu down stream Subwatershed are respectively $125.16 \mathrm{~m}^{3} / \mathrm{sec}$ (2 years return period), $145.24 \mathrm{~m}^{3} / \mathrm{sec}$ (5 years return period), $157.59 \mathrm{~m}^{3} / \mathrm{sec}$ (10 years return period), $172.43 \mathrm{~m}^{3} / \mathrm{sec}$ (25 years return period), $183.03 \mathrm{~m}^{3} / \mathrm{sec}$ (50 years return period) and $193.34 \mathrm{~m}^{3} / \mathrm{sec}$ (100 years return period).
\end{abstract}

Keywords: Watershed, Air Bengkulu, Design Discharge, Frequency Analysis, Distribution Analysis

\section{Abstrak}

Debit rancangan merupakan data utama yang sangat dibutuhkan dalam merencanakan bangunan air. Tujuan dari penelitian ini adalah mengestimasi debit rancangan dengan berbagai kala ulang menggunakan analisa frekuensi distribusi data hujan di Sub DAS Air Bengkulu Hilir. Data Hujan diperoleh dari BMKG provinsi Bengkulu mulai dari tahun 2009 - 2018. Metode estimasi debit banjir rancangan pada penelitian ini menggunakan metode statistic menggunakan metode distribusi. Tahap awal dari penelitian adalah mengolah data hujan lalu melakukan analisis

\section{Informasi Artikel}

Diterima Redaksi : 18-02-2020 | Selesai Revisi : 15-04-2020 | Diterbitkan Online : 23-04-2020 
${ }^{1}$ Gusta Gunawan, ${ }^{2}$ Besperi, ${ }^{3}$ Liza Purnama

Jurnal IImiah Rekayasa Sipil Vol.17 No.1 Edisi April 2020

frekuensi. Persamaan matematis untuk analisis frekuensi meliputi persamaan statistic untuk menentukan nilai rata-rata, standar deviasi, koefisien variasi, koefisien kemiringan, dan koefisien kurtosis.Cara yang digunakandalam penentuan jenis sebaran untuk analisisfrekuensi dalam penelitian ini menggunakan metode distribusiGumbelTipe I,LogPearson TipellI, Normal, danLog Normal. Uji kecocokan distribusi dilakukan dengan uji chi kuadrat dan uji Smirnov Kalmogorof. Hasil estimasi debit rancangan untuk kala ulang 2, 5, 10, 25, 50 dan 100 tahun di Sub DAS Air Bengkulu Hilir masing-masing nilainya secara berurutan adalah sebesar 125,16 $\mathrm{m}^{3} /$ detik (kala ulang 2 tahun), 145,24 m³/detik (kala ulang 5 tahun), 157,59 m³/detik (kala ulang 10 tahun), 172,43 $\mathrm{m}^{3} /$ detik (kala ulang 25 tahun), 183,03 m³/detik (kala ulang 50 tahun) dan 193,34 m³/detik (kala ulang 100 tahun).

Kata kunci: DAS,Air Bengkulu, Debit Rancangan, Analisis Frekuensi, Analisis Distribusi

(C) 2020 Jurnal Ilmiah Rekayasa Sipil

\section{Pendahuluan}

Das Air Bengkulu terbagi dalam 3 SubDAS yaitu Sub-DAS Rindu Hati mencakup area seluas 19.207 ha, Sub-DAS Susup mencakup area seluas 9.890 ha, dan SubDAS Bengkulu Hilir mencakup area seluas 22.402 ha [1]. DAS Air Bengkulu termasuk dalam DAS kritis sehingga perlu mendapat perhatian serius. Kondisi kritis ini muncul karena alih fungsi lahan hutan menjadi fungsi lain di kawasan DAS Air Bengkulu bagian hulu. Akibat dari alih fungsi lahan tersebut menyebabkan Kota Bengkulu mengalami banjir setiap tahunnya.

Pengendalian banjir perlu dilakukan untuk menurunkan tingkat risiko kerugian baik kerugian harta benda maupun kerugian jiwa. Pengendalian banjir dapat dilakukan dengan upaya-upaya secara struktural maupun nonstruktural. Upaya secara struktural dapat berupa tindakan menormalisasi sungai, pembangunan waduk pengendali banjir, pengurangan debit puncak banjir, dan lain-lain.
Pemerintah Kota Bengkulu berencana untuk melakukan upaya pengendalian banjir dengan cara membangun embung di beberapa tempat.

Akan tetapi informasi mengenai debit banjir rancangan untuk Sub DAS Bengkulu bagian hilir masih sedikit. Padahal, informasi mengenai debit banjir rancangan sangat dibutuhkan sekali dalam perencanaan.

Banyak para peneliti melakukan analisis debit banjir menggunakan hidrograf satuan sintetis dengan HSS Nakayasu dan ITB [6], [7], HSS Gama I dan Limantara [9], [10]. Para peneliti yang telah melakukan penelitian debit puncak di Sub DAS Air Bengkulu Hilir adalah [3], [5]. Debit puncak diestimasi oleh kedua peneliti tersebut menggunakan hidrograf satuan sintetis. Pemodelan luapan banjir Sungai Air Bengkulu diteliti oleh [13].

Akan tetapi, estimasi debit menggunakan HSS membutuhkan data DAS yang agak kompleks sehingga membutuhkan waktu yang lama untuk mengolah datanya. Padahal

\section{Informasi Artikel}

Diterima Redaksi : 18-02-2020 | Selesai Revisi : 15-04-2020 | Diterbitkan Online : 23-04-2020 
estimasi debit rancangan juga bisa dilakukan menggunakan metode statistik [12].

Oleh karena itu, penelitian ini bertujuan untuk menentukan debit banjir rancangan pada sub DAS Air Bengkulu bagian hilir menggunakan analisis frekuensi dan distribusi untuk berbagai kala ulang.

\section{Metode Penelitian}

\section{Lokasi Penelitian}

Penelitian ini dilakukan pada Sub-DAS Bengkulu Hilir.

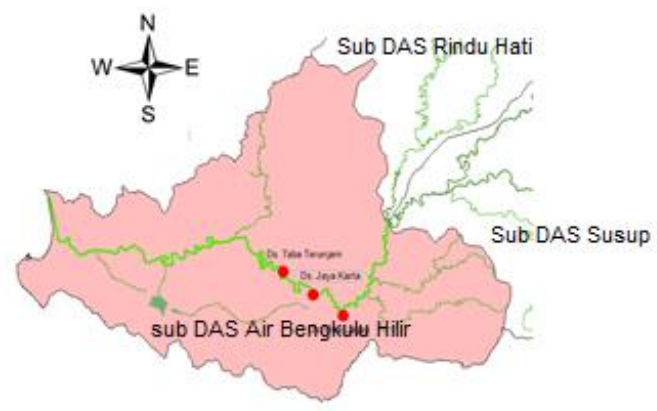

Gambar 1.Lokasi Penelitian

Sumber : BPDAS Ketahun, 2019

\section{Pengumpulan Data}

Data-data yang dikumpulkan data curah hujan dari Badan Meteorologi, Klimatologi dan Geofisika Bengkulu. Data curah hujan yang digunakan data curah hujan harian maksimum selama 10 tahun terakhir sejak tahun 2009 hingga tahun 2018 dari lima pos hujan.

\section{Peralatan Penelitian}

Peralatan yang digunakan pada penelitian ini berupa Seperangkat komputer (PC), Microsoft Word dan Microsoft Excel, Alat tulis, Kalkulator,

\section{Distribusi Curah Hujan Rata-Rata Wilayah}

Data curah hujan yang dipakai untuk perhitungan debit banjir adalah hujan yang terjadi pada daerah aliran sungai pada waktu yang sama. Cara perhitungan curah hujan menggunakan metode poligon Thiessen [8].Metode ini cocok jika stasiun hujan tidak tersebar merata dan jumlahnya terbatas dibanding luasnya.

\section{Analisa Frekuensi}

Data yang digunakan untuk analisis frekuensi adalah data hujan 10 tahun mulai dari sejak tahun 2009 hingga tahun 2018 dari lima pos hujan. Perhitungan analisis frekuensi meliputi parameter nilai rata-rata, standar deviasi, koefisien variasi, koefisien kemiringan, dan koefisien kurtosis. Persamaan yang digunakan adalah sebagai berikut:

1. Nilai rata-rata

$$
\bar{X}=\frac{\sum_{i-1}^{n} X_{i}}{n}
$$

2. Standar deviasi

$$
S d=\sqrt{\frac{\sum_{i-1}^{n}\left(X_{i}-\bar{X}\right)^{2}}{n-1}}
$$

3. Koefisien kemiringan

$$
C s=\frac{n \sum_{i-1}^{n}\left\{\left(X_{i}\right)-\bar{X}\right\}^{3}}{(n-1)(n-2) S d^{3}}
$$

4. Koefisien kurtosis

$$
C k=\frac{\frac{1}{n} \sum_{i-1}^{n}\left\{\left(X_{i}\right)-\bar{X}\right\}^{4}}{S d^{4}}
$$

5. Koefisien variasi

$$
C v=\frac{S d^{4}}{\bar{X}}
$$

Dimana :

Sd =Deviasi standar

Cs =Koefisien kemiringan (Skewness)

\section{Informasi Artikel}

Diterima Redaksi : 18-02-2020 | Selesai Revisi : 15-04-2020 | Diterbitkan Online : 23-04-2020 


$$
\begin{array}{ll}
\mathrm{Ck} & =\text { Koefisien kurtosis } \\
\mathrm{Cv} & =\text { Koefisien variasi } \\
\mathrm{X}_{\mathrm{i}} & =\text { =Nilai varian kei } \\
\bar{X} & =\text { Nilai rata-rata varian } \\
\mathrm{n} & =\text { Jumlah data }
\end{array}
$$

\section{Pemilihan Jenis Sebaran}

Masing-masing sebaran memiliki sifatsifat khas sehingga setiap data hidrologi harus diuji kesesuaiannya dengan sifat statistik masing-masing sebaran tersebut. Cara yang digunakandalam penentuan jenis sebaran untuk analisis frekuensi dalam penelitian ini adalah distribusi Gumbel Tipe I, Log Pearson Tipe III, Normal, dan Log Normal [8].

\section{a. Distribusi Gumbel Tipel}

Persamaan distribusi frekuensi empiris yang digunakan untuk menghitung curah hujan rancangan sebagai berikut (Soemarto, 1999):

$$
X_{T}=\bar{X}+\frac{s}{s_{n}}\left(Y_{T}-Y_{n}\right)
$$

Dimana:

$\mathrm{X}_{\mathrm{T}}=$ Nilai hujan rencanadengan data ukurT tahun(mm)

$\overline{\mathrm{X}} \quad=$ Nilai rata-rata hujan $(\mathrm{mm})$

$\mathrm{S} \quad=$ Deviasi standar (simpangan baku)

$=\sqrt{\frac{\sum\left(x_{i}-\bar{x}\right)^{2}}{n-1}}$

$\mathrm{Y}_{\mathrm{T}}=$ = Nilai reduksi variat (reduced variate) dari variable yang diharapkan terjadi pada periode ulang $\mathrm{T}$ tahun, dapat dihitung dengan rumus:

$=-\ln \left[-\ln \frac{T-1}{T}\right] ;$ untuk $\mathrm{T} \geq 20$, maka $\mathrm{Y}$

$$
=\ln \mathrm{T}
$$

$Y_{n}=$ Nilai rata-rata dari reduksi variat (reducedmean) nilai nya tergantung dari jumlah data (n)

\section{b. Distribusi Log Pearson Tipe III}

Metode Log Pearson Tipe III menggunakan persamaan sebagai berikut (Soemarto, 1999):

$Y=\bar{Y}+k \times S$

Dimana:

$Y=$ Nilai logaritmik dari $\mathrm{X}$ atau $\log \mathrm{X}$

$X=$ Curah hujan $(\mathrm{mm})$

$\bar{Y}=$ Rata-rata hitung (lebih baik rata-rata geometrik) nilai $Y$

$S=$ Deviasi standar nilai $Y$

$K=$ Karakteristik distribusi peluang LogPerson Tipe III

\section{c. Distribusi Normal}

Persamaan distribusi normal yang digunakan sebagai berikut:

$P\left(X_{1}<X<X_{2}\right)=\int_{x 1}^{x 2} \frac{1}{\sigma \sqrt{2 \pi}} \times e^{\frac{1}{-2}\left[\frac{X-\mu}{\sigma}\right]^{2}} d x$

\section{d. Distribusi Log Normal}

Persamaan distribusi Log Normal yang akan digunakan sebagai berikut (Soerwarno, 1995):

$X_{T}=\bar{X}+K t \times S$

Dimana:

$X_{T}=$ Besarnya curah hujan yang mungkin terjadi dengan periode ulang $X$ tahun (mm)

$\bar{X}=$ Curah hujan rata-rata $(\mathrm{mm})$

$K t=$ Standar variable untuk periode ulang $\mathrm{T}$ tahun

$S=$ Deviasi standar data hujan maksimum tahunan

Adapun syarat masing-masing jenis distribusi yang digunakan seperti pada Tabel 1 berikut

\section{Informasi Artikel}

Diterima Redaksi : 18-02-2020 | Selesai Revisi : 15-04-2020 | Diterbitkan Online : 23-04-2020 
Tabel 1. Persyaratan Parameter Statistik

\begin{tabular}{ll}
\hline \multicolumn{1}{c}{ Distribusi } & Persyaratan \\
\hline Normal & $\mathrm{Cs} \approx 0$ \\
& $\mathrm{Ck} \approx 3$ \\
LogNormal & $\mathrm{Cs} \approx \mathrm{Cv}^{3}+3 \mathrm{Cv}$ \\
& $\mathrm{Ck} \approx \mathrm{Cv}^{8}+6 \mathrm{Cv}^{6}+15 \mathrm{Cv}^{4}+16 \mathrm{Cv}^{2}+3$ \\
Gumbel & $\mathrm{Cs} \approx 1,14$ \\
LogPearsonllI & $\mathrm{Ck} \approx 5.4$ \\
& Selain dari nilai diatas \\
\hline
\end{tabular}

Sumber :Robot, 2014

\section{Pengujian Kecocokan Sebaran}

Ada dua jenis uji kecocokan sebaran yang dilakukan yaitu uji Kecocokan Chi-Kuadrat (Chi- Square) dan uji Kecocokan SmirnovKolmogorov [12].

\section{Uji Kecocokan Chi-Kuadrat (Chi-Square)}

Persamaan matematis yang digunakan untuk pengujian dengan metode kecocokan Chi Kuadrat adalah sebagai berikut :

$$
X^{2}=\sum_{t-1}^{n} \frac{(O i-E i)^{2}}{E i}
$$

\section{Dimana:}

$\mathrm{X}^{2}=$ Harga Chi-Square terhitung

$\mathrm{Ei}=$ Jumlah nilai teoritis pada sub kelompok kei

$\mathrm{Oi}=$ Jumlahnilai pengamatan padasub kelompok kei

$\mathrm{N}=$ Jumlah data

Suatu distribusi dikatakan selaras jika nilai $X^{2}$ hitung $<X^{2}$ kritis.

Nilai nyata tertentu (levelofsignificant) yang sering diambil adalah $5 \%$.Derajat kebebasan ini secara umum dihitung dengan rumus sebagai berikut [12].

$D k=K-(P+1)$

Dimana:

Dk $=$ Derajat kebebasan

$\mathrm{P}=$ Nilai untuk distribusi

\section{Uji Kecocokan}

\section{Kolmogorov}

Perbedaan maksimum yang dihitung ( $\Delta$ maks) dibandingkan dengan perbedaan kritis $(\Delta c r)$ untuk suatu derajat nyata dan banyaknya variat tertentu, maka sebaran sesuai jika $(\Delta$ maks $)<(\Delta c r)$. Pengujian menggunakan rumus sebagai berikut [12].

$$
\alpha=\frac{P_{m a k s}}{P_{(x)}}-\frac{P_{(x)}}{\Delta_{c r}}
$$

\section{Debit Banjir Rancangan}

Debit banjir rancangan dihitung berdasarkan jenis distribusi di sub DAS Air Bengkulu Hilir dengan kala ulang 2, 5, 10, 25, 50 dan 100 tahun

\section{Hasil dan Pembahasan}

Data curah hujan diperoleh dari 5 (lima) pos hujan yang terletak di sub DAS Air Bengkulu Hilir.

\section{Informasi Artikel}

Diterima Redaksi : 18-02-2020 | Selesai Revisi : 15-04-2020 | Diterbitkan Online : 23-04-2020 
Tabel 2.Data Curah Hujan DAS Air Bengkulu

\begin{tabular}{|c|c|c|c|c|c|c|}
\hline \multirow{2}{*}{ Tahun } & \multicolumn{5}{|c|}{ Rh max Stasiun (mm) } & \multirow{2}{*}{$\begin{array}{c}\text { Rh max } \\
\text { rata-rata } \\
\text { (mm) }\end{array}$} \\
\hline & MB & JK & TJ & UB & TM & \\
\hline 2009 & 113 & 162 & 151 & 201 & 164 & 158,11 \\
\hline 2010 & 125 & 155 & 122 & 159 & 98 & 131,88 \\
\hline 2011 & 106 & 117 & 95 & 168 & 91 & 115,36 \\
\hline 2012 & 102 & 84 & 224 & 165 & 71 & 129,14 \\
\hline 2013 & 162 & 168 & 80 & 163 & 104 & 135,34 \\
\hline 2014 & 79 & 101 & 131 & 156 & 88 & 110,94 \\
\hline 2015 & 76 & 108 & 113 & 135 & 88 & 103,94 \\
\hline 2016 & 71 & 151 & 198 & 198 & 130 & 149,58 \\
\hline 2017 & 79 & 200 & 175 & 180 & 127 & 152,14 \\
\hline 2018 & 61 & 149 & 186 & 202 & 62 & 131,98 \\
\hline $\begin{array}{l}\text { Rata- } \\
\text { Rata }\end{array}$ & 97 & 140 & 148 & 173 & 102 & 131,84 \\
\hline
\end{tabular}

Sumber :BMKG Provinsi Bengkulu, 2019

Keterangan :MB= Muara Bangkahulu, $J K=$ Jaya Karta, $T J$

= Tanjung Jaya, UB = Universitas Bengkuu, $T M=$ Taba Mutung

Data curah hujan rerata maksimum pada Tabel 1 diurutkan dari data hujan yang kecil ke yang besar dan hasilnya disajikan pada Tabel 3.

Tabel 3. Data Curah Hujan Rerata Tahunan dari Kecil Terbesar

\begin{tabular}{ccc}
\hline No & Tahun & R $_{\text {thiessen }}(\mathbf{m m})$ \\
\hline 1 & 2015 & 101,405 \\
2 & 2011 & 103,624 \\
3 & 2014 & 104,976 \\
4 & 2012 & 120,990 \\
5 & 2013 & 123,207 \\
6 & 2010 & 125,921 \\
7 & 2018 & 126,224 \\
8 & 2016 & 152,578 \\
9 & 2009 & 157,503 \\
10 & 2017 & 160,373 \\
\hline
\end{tabular}

\section{Analisa Frekuensi}

Hasil perhitungan Parameter Statistik (Pengukuran Dispersi) yang telah dilakukan sebagai berikut :

\begin{tabular}{|c|c|}
\hline Rata-rata & $: 127,68$ \\
\hline Standar Deviasi & : 22,19 \\
\hline Koefisien Kemencengen (Cs) & 0,42 \\
\hline Koefisien Kurtosis (Ck) & 1,2 \\
\hline Koefisien Variasi (Cv) & 0,17 \\
\hline
\end{tabular}

\section{Pemilihan Jenis Sebaran}

Pemilihan jenis sebaran data hujan dilakukan dengan menggunakan kriteria yang terdapat pada Tabel 1 lalu membandingkan nilainya dengan persyaratan yang diminta untuk masing-masing distribusi. Persyaratan untuk masing-masing jenis distribusi disajikan pada Tabel 4 berikut.

Tabel 4. Persyaratan Jenis Sebaran

\begin{tabular}{llr}
\hline Jenis Distribusi & \multicolumn{1}{c}{ Persyaratan } & Keterangan \\
\hline Normal & $\mathrm{Cs} \approx 0$ & Tidak \\
& $\mathrm{Ck} \approx 3$ & Tidak \\
LogNormal & $\mathrm{Cs} \approx 2$ & \\
& $\mathrm{Ck} \approx 10,11$ & Tidak \\
Gumbel & $\mathrm{Cs} \approx 1,14$ & \\
LogPearsonlll & $\mathrm{Ck} \approx 5.4$ & Ya \\
\end{tabular}

Sumber : Data Primer, 2019

Dari Tabel 4 diketahui bahwa distribusi data hujan di Sub DAS Air Bengkulu Hilir termasuk pada distribusi Log Pearson tipe III.

\section{Pengujian Kecocokan Sebaran}

Pengujian kecocokan sebaran Metode Log Pearson Tipe III dilakukan dengan menggunakan uji kecocokan sebaran Chi-

\section{Informasi Artikel}

Diterima Redaksi : 18-02-2020 | Selesai Revisi : 15-04-2020 | Diterbitkan Online : 23-04-2020 
Kuadrat (Chi-Square) dan Uji Kecocokan Smirnov-Kolmogorov.

Pengujian dengan Chi-Kuadrat (Chi-Square) menggunakan Jumlah kelas $(K)$ sebanyak 5 , Derajat kebebasan (DK) 3, Ei $=2, \Delta \mathbf{X}=\mathbf{1 5}$. Perhitungannya diperagakan pada Tabel 5.

Tabel 5. Perhitungan Uji Chi Kuadrat

\begin{tabular}{|c|c|c|c|c|c|c|}
\hline \multirow{3}{*}{ No } & & & \multicolumn{4}{|c|}{ Jumlah } \\
\hline & \multicolumn{3}{|c|}{ Probabilitas (\%) } & \multicolumn{2}{|c|}{ Data } & \multirow[t]{2}{*}{$\mathbf{X}^{2}$} \\
\hline & & & & Oi & Ei & \\
\hline 1 & 93,905 & $<x<$ & 108,905 & 3 & 2 & 0,50 \\
\hline 2 & 108,905 & $<x<$ & 123,905 & 2 & 2 & 0,00 \\
\hline 3 & 123,905 & $<x<$ & 138,905 & 2 & 2 & 0,00 \\
\hline 4 & 138,905 & $<x<$ & 153,905 & 1 & 2 & 0,50 \\
\hline 5 & 153,905 & $<x<$ & 168,905 & 2 & 2 & 0,00 \\
\hline & & ah & & 10 & 2 & 1 \\
\hline
\end{tabular}

Sumber : Data Primer, 2019

Dari Tabel 5 didapatkan nilai $X^{2}$ hasil hitungan $=1$ sedangkan niliai dari $X^{2} \mathrm{Cr}=7,815$ sehingga $X^{2}$ hitungan lebih kecil dari nilai $X^{2} \mathrm{Cr}$ maka hipotesa yang diuji dapat diterima.

Selanjutnya pengujian sebaran kecocokan Smirnov-Kolmogorov dilakukan menggunakan nilai rata-rata curah hujan (Xrt) sebesar 127,680 mm, Standar Deviasi (SD) sebesar 22,19, Jumlah data (n) sebanyak 10, Derajat kepercayaan ( $\alpha$ ) sebesar $5 \%$ maka diperoleh :

$$
D_{\text {maks }}=0,202
$$

$$
\mathrm{D} 0_{\text {kritis }}=0,41
$$

Nilai Do kritis didapat dari tabel dengan cara melihat jumlah data (n) dihubungkan pada derajat kepercayaan $(\alpha)$.

Dari perbandingan di atas dapat diketahui bahwa $D_{\text {maks }}(0,202)<D 0_{\text {kritis }}(0,41)$, maka metode sebaran yang diuji dapat diterima.

Hasil perhitungan rinci dari uji kecocokan sebaran menggunakan uji kecocokan SmirnovKolmogorov disajikan pada Tabel 6 .

Tabel 6. Uji Smirnov- Kolmogorov

\begin{tabular}{ccccccc}
\hline $\log \mathbf{X i}$ & $\mathbf{M}$ & $\mathbf{P}(\mathbf{x})$ & $\mathbf{P}(\mathbf{x}<)$ & $\mathbf{f}(\mathbf{t})$ & $\mathbf{P}^{\prime}(\mathbf{x}<)$ & $\mathbf{D}$ \\
$\mathrm{a}$ & $\mathrm{b}$ & $\mathrm{c}$ & $\mathrm{d}$ & $\mathrm{e}$ & $\mathrm{f}$ & $\mathrm{g}$ \\
\hline 93,12 & 1 & 0,09 & 0,91 & $-1,18$ & 0,89 & 0,020 \\
101,41 & 2 & 0,18 & 0,82 & $-1,08$ & 0,78 & 0,040 \\
103,62 & 3 & 0,27 & 0,73 & $-1,02$ & 0,67 & 0,061 \\
104,98 & 4 & 0,36 & 0,64 & $-0,30$ & 0,56 & 0,081 \\
120,99 & 5 & 0,45 & 0,55 & $-0,20$ & 0,44 & 0,101 \\
123,21 & 6 & 0,55 & 0,45 & $-0,08$ & 0,33 & 0,121 \\
125,92 & 7 & 0,64 & 0,36 & $-0,07$ & 0,22 & 0,141 \\
126,22 & 8 & 0,73 & 0,27 & 1,12 & 0,11 & 0,162 \\
152,58 & 9 & 0,82 & 0,18 & 1,34 & 0,00 & 0,182 \\
160,37 & 10 & 0,91 & 0,09 & 1,47 & $-0,11$ & $\mathbf{0 , 2 0 2}$
\end{tabular}

Sumber : Data Primer, 2019

Berdasarkan uji kecocokan yang telah dilakukan dengan dua metode yaitu uji Chi Kuadrat dan Smirnov Kolmogorov maka distribusi data hujan di Sub DAS Air Bengkulu Hilir mengikuti distribusi Log Person III.

\section{Debit Banjir Rancangan}

Debit banjir rancangan dihitung berdasarkan distribusi Log Person Tipe III dengan kala

\section{Informasi Artikel}

Diterima Redaksi : 18-02-2020 | Selesai Revisi : 15-04-2020 | Diterbitkan Online : 23-04-2020 
ulang 2, 5, 10, 25, 50 dan 100 tahun. Hasil perhitungannya disajikan pada Tabel 7 .

Tabel 7. Perhitungan Debit Rancangan

\begin{tabular}{ccccccc}
\hline $\operatorname{tr}$ & $\overline{\log (X)}$ & $\overline{\mathbf{S d} \log X}$ & $\mathbf{C s}$ & $\mathbf{K}$ & $\mathbf{Y}$ & $\mathbf{X}_{\text {tr }}$ \\
\hline 2 & 2,100 & 0,07 & 0,23 & 0,038 & 2,10 & 125,16 \\
5 & 2,100 & 0,07 & 0,23 & 0,828 & 2,16 & 145,24 \\
10 & 2,100 & 0,07 & 0,23 & 1,303 & 2,20 & 157,59 \\
25 & 2,100 & 0,07 & 0,23 & 1,827 & 2,24 & 172,43 \\
50 & 2,100 & 0,07 & 0,23 & 2,174 & 2,26 & 183,03 \\
100 & 2,100 & 0,07 & 0,23 & 2,493 & 2,29 & 193,34
\end{tabular}

Sumber : Data Primer, 2019

Hasil estimasi debit rancangan untuk kala ulang 2, 5, 10, 25, 50 dan 100 tahun di Sub DAS Air Bengkulu Hilir masing-masing nilainya secara berurutan adalah sebesar 125,16 $\mathrm{m}^{3} /$ detik (kala ulang 2 tahun), 145,24 $\mathrm{m}^{3} /$ detik (kala ulang 5 tahun), 157,59 m³/detik (kala ulang 10 tahun), 172,43 $\mathrm{m}^{3} /$ detik (kala ulang 25 tahun), 183,03 m³/detik (kala ulang 50 tahun) dan 193,34 $\mathrm{m}^{3} /$ detik (kala ulang 100 tahun).

\section{Kesimpulan}

Berdasarkan keseluruhan hasil analisa data yang dilakukan dalam penelitian ini dapat ditarik kesimpulan sebagai berikut :

1. Distribusi data hujan di Sub DAS Air Bengkulu Hilir termasuk pada distribusi Log Pearson tipe III.

2. Hasil uji kecocokan distribusi dengan dua metode yaitu uji Chi Kuadrat dan Smirnov Kolmogorov maka distribusi Log Person III untuk sebaran data hujan di Sub DAS Air Bengkulu Hilir dapat diterima.
3. Debit rancangan untuk kala ulang 2, 5, 10, 25, 50 dan 100 tahun secara berurutan nilainya sebesar 125,16 m³/detik, 145,24 $\mathrm{m}^{3} /$ detik, $157,59 \mathrm{~m}^{3} /$ detik, $172,43 \mathrm{~m}^{3} /$ detik, $183,03 \mathrm{~m}^{3} /$ detik dan 193,34 m³/detik.

\section{Ucapan Terima Kasih}

Penulis mengucapkan terima kasih kepada pimpinan Universitas Bengkulu dan pimpinan Fakultas Teknik UNIB yang sangat membantu proses administrasi penelitian ini. Ucapan terima kasih juga disampaikan kepada pimpinan BMKG Provinsi Bengkulu, BP DAS Ketahun dan BWS Sumatera VII yang telah membantu data-data hujan dan data-data lainnya.

\section{Daftar Pustaka}

[1] Ardiansyah, O., \& Mustikasari, R. (2011). Gambaran Umum Permasalahan Pengelolaan Air DAS Air Bengkulu. Telapak

[2] BPDAS Ketahun (2019), Batas DAS Air Bengkulu, http://sipdas.menlhk.go.id/

[3] Kurniawan, O. (2019). Analisis Debit Puncak Menggunakan Pendekatan Metode Hidrograf Satuan Sintetis (HSS) Snyder dan HEC-RAS

[4] Versi 5.0.7 (Studi Kasus DAS Air Brngkulu di Bagian Hilir). Bengkulu: Universitas Bengkulu.

[5] Mareta, P. E. (2019). Analisis Debit Puncak DAS Air Bengkulu Bagian Hilir Menggunakan Pendekatan Metode Hidrograf Satuan Sintetis Soil

\section{Informasi Artikel}

Diterima Redaksi : 18-02-2020 | Selesai Revisi : 15-04-2020 | Diterbitkan Online : 23-04-2020 
Conservation Service (HSS SCS) dan Program HEC-RAS 5.0.7. Bengkulu: Universitas Bengkulu.

[6] Margini, N., Nusantara, D., \& Ansori, M. (2017). Analisis Hidrograf Satuan Sintetis Nakayasu dan ITB Pada Sub DAS Konto, Jawa Timur. Jurnal Teknik HIdroteknik Vol. 2 No. 1.

[7] Natakusumah, D. K., Hatmoko,W., Harlan, D., (2011). Prosedur Umum Perhitungan Hidrograf Satuan Sintetisdengan Cara ITB dan Beberapa Contoh Penerapannya. Jurnal teknik Sipil 18(3): 251-291.

[8] Negoro, A. N., \& Pramawan, H. (2008). Perencanaan Teknis Embung Silandak Sebagai Pengendali Banjir Kali Silandak Semarang. Semarang: Universitas Diponegoro Semarang

[9] Rapar, S., Mananoma, T., Wuisan, E., \& Binilang, A. (2014). Analisis Debit Banjir Sungai Tondano Menggunakan Metode HSS Gama I dan HSS Limantara. Jurnal Sipil Statisatik Vol. 2 No. 1.
[10] Robot, J. A. (2014). Analisis Debit Banjir Sungai Ranoyapo Menggunakan Metode HSS GAMA-I dan HSS Limantara. Jurnal Sipil Statistik Vol. 2 No.1.

[11] Sebastian, L. (2008). Pendekatan Pencegahan dan Penanggulangan Banjir. Dinamika Teknik Sipil Vol. 8 No. 2.

[12] Soerwarno. (1995). Hidrologi Aplikasi Metode Statistik Untuk Analisa Data Jilid 1. Bandung: Nova.

[13] Suryatmo, I. S. (2016). Pemodelan Luapan Banjir Sungai Air Bengkulu Menggunakan HEC- GeoRAS. Bengkulu: Fakultas Teknik Universitas Bengkulu.

[14] Soemarto. (1986). Hidrologi Teknik. Surabaya: Usaha Nasional.

[15] Syarifudin, A. (2017). Hidrologi Terapan. Yogyakarta: Andi.

[16] Timur, H. M. (2017). Stabilitas Talud dan Bendung Untuk Embung memanjang Desa Ngawu, Kecamatan playen, Kabupaten Kidul, Yogyakarta. Yogyakarta: Universitas Atma Jaya Yogyakarta.

\section{Informasi Artikel}

Diterima Redaksi : 18-02-2020 | Selesai Revisi : 15-04-2020 | Diterbitkan Online : 23-04-2020 